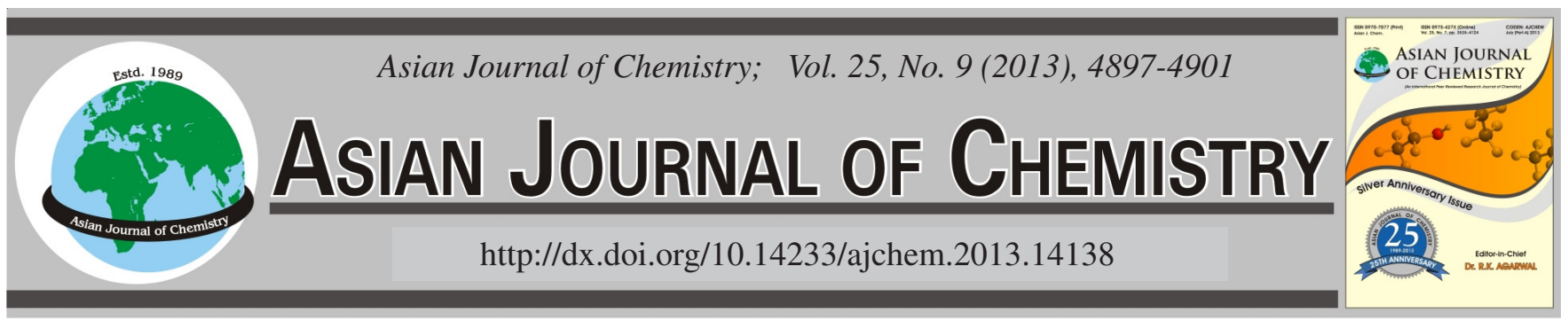

\title{
Spatial Distribution of Heavy Metals in the Farmland at the Confluence of Songhua and Heilong Rivers, China
}

\author{
J.T. $\mathrm{NIU}^{1,2, *}$, Q.H. WANG ${ }^{1,3, *}$, Q.K. Guo ${ }^{4}$, Y. $\mathrm{LI}^{5}$ and F.S. $\mathrm{Li}^{6}$
}

${ }^{1}$ State Key Laboratory of Urban Water Resource and Environment, Harbin Institute of Technology, Harbin 150090, P.R. China ${ }^{2}$ College of Life Sciences, Jiamusi University, Jiamusi 154007, P.R. China

${ }^{3}$ Department of Environmental Engineering, University of Science and Technology Beijing, Beijing 100083, P.R. China

${ }^{4}$ Agricultural Products Quality Inspection Center of Jiamusi City, Jiamusi 154007, P.R. China

${ }^{5}$ Environmental Protection Bureau of Jiamusi City, Jiamusi 154002, P.R. China

${ }^{6}$ Chinese Research Academy of Environmental Sciences, Beijing 100012, P.R. China

*Corresponding authors: Tel/Fax: +86454 8617780; E-mail: wangqh59@sina.com; njtyc@ sohu.com

\begin{abstract}
Sanjiang plain, which is an alluvial land situated at the confluence of Songhua, Heilong and Ussuri Rivers in northeast of China, is an important commodity grain base. Within the confluence zone, the contents of five heavy metals $(\mathrm{Cd}, \mathrm{Hg}, \mathrm{As}, \mathrm{Pb}$ and $\mathrm{Cr})$ in surface soils were sampled and monitored in 21 villages around Tongjiang, Fujin and Suibin Cities. Spatial distribution analysis and assessment were conducted by using GIS technology, Müller geoaccumulation index and Håkanson potential ecological risk index. Heavy metal contents in the studied area range as follows: $\mathrm{Cd}, 0.048-0.280 \mathrm{mg} / \mathrm{kg} ; \mathrm{Hg}, 0.017-0.079 \mathrm{mg} / \mathrm{kg}$; As, 4.73-18.16 mg/kg; Pb, $15.9-34.8 \mathrm{mg} / \mathrm{kg}$ and Cr, $16.8-55.1 \mathrm{mg} / \mathrm{kg}$, indicating that the detection results meet the agricultural industry standard of China, i.e., environmental condition standards for pollution-free food production (NY5332-2006). Statistical analysis showed that there are certain correlations among Cd, As and $\mathrm{Pb}$. In Fujing City, the southwest region of the studied area, $\mathrm{Cd}$, As and $\mathrm{Pb}$ levels are elevated. $\mathrm{Hg}$ distribution is dispersed and $\mathrm{Cr}$ level is elevated in the eastern and southern parts of the studied area. Moreover, the calculations of Müller geoaccumulation index and Håkanson potential ecological risk index indicate that light pollution is caused by $\mathrm{Cd}$ and $\mathrm{As}$ and that the majority of the studied area is exposed to slight ecological risk.

Key Words: Soil, Heavy metals, Spatial distribution, Geoaccumulation index, Sanjiang plain.
\end{abstract}

\section{INTRODUCTION}

Due to its persistence and potential ecological risk, heavy metal pollution in soil and river sediment has increasingly been regarded as a serious problem in recent years ${ }^{1-4}$. Along with the implementation of Chinese national strategies pollutionfree agriculture, food safety and ecology safety, heavy metal pollution has progressively been attached considerable importance.

Sanjiang plain is an alluvial land situated at the confluence of Songhua, Heilong and Ussuri Rivers in northeast of China (Fig. 1), rich in soybean, rice, corn and beet. It is one of the only three belts of black soil in the world and known as an important commodity grain base. The large-scale immigration and cultivation in 1950s led to over development of Sanjiang plain and decrease in wetland area of as high as $80 \%$. The natural ecosystem has been transformed into an artificialnatural compound system and the harmony between economic development and environmental protection is being threatened,

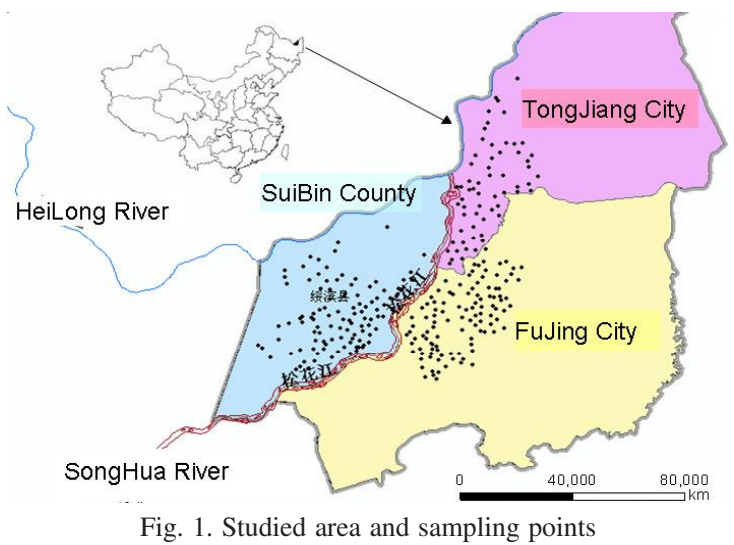

thereby exposing sustainable agriculture to risk $^{5,6}$. In recent years, increasing attention has been paid to the ecology and environment of Sanjiang Plain. Wang et al. ${ }^{7}$ and Zhang et al. ${ }^{6}$ conducted evaluation on the land-use change of Sanjiang plain and concluded that wetland is shrinking due to land reclamation. 
Liu et $a l .{ }^{8}$ indicated that the number of species decreased greatly due to reclamation. Lu et al. ${ }^{9}$ chose ditch density as an indicator of disturbance intensity and showed that the wetlands tended to be reduced in plant species diversity with increasing disturbance intensity. To evaluate wetland soil quality degradation caused by agricultural reclamation in Sanjiang Plain, Wang et al. ${ }^{10}$ established two fuzzy synthetic evaluation (FSE) models successfully. To investigate the effect of wetland on global warming, a large number of studies have also been conducted to study the fluxes of greenhouse gas $\mathrm{CO}_{2}, \mathrm{CH}_{4}$, $\mathrm{N}_{2} \mathrm{O}$ in Sanjiang Plain ${ }^{11,12}$. However, few studies are focused on the investigation of heavy metal pollution in Sanjiang plain.

To elucidate the current heavy metal accumulation in soil caused by external factors such as industrial waste emission, wastewater irrigation, excessive utilization of fertilizer and pesticide, this study sampled the surface soil in Sanjiang Plain to evaluate the pollution of $\mathrm{Cd}, \mathrm{Hg}, \mathrm{As}, \mathrm{Pb}$ and $\mathrm{Cr}$ by using GIS technology, Müller geoaccumulation index and Håkanson potential ecological risk index. Study results of this paper might be helpful for pollution control and improvement of agricultural productivity.

Studied area: The studied area (latitude $47.12-47.97^{\circ} \mathrm{N}$ and longitude $131.44-132.98^{\circ} \mathrm{E}$ ) is located at east of Sanjiang Plain in Heilongjiang province, China. It's an alluvial land situated at the confluence of Songhua and Heilong Rivers around three counties of Suibin, Tongjiang and Fujing (Fig. 1). Within the confluence zone, surface soils were sampled and monitored the contents of five heavy metals $(\mathrm{Cd}, \mathrm{Hg}, \mathrm{As}, \mathrm{Pb}$ and $\mathrm{Cr}$ ) in 21 villages. The general topology of the region is characterized by high altitude at the southeastern area and low altitude at the northwestern portion, consisting of gentle hilly, plain and low plain. The area is $4,700 \mathrm{~km}^{2}$, with altitude of 52-65 m. Seven soil types are distributed in this area e.g., dark brown soils, albic soil, black soil, meadow soil, marsh soil, peat soil and paddy soil. Average temperature in this area is $2.7^{\circ} \mathrm{C}$ and the mean annual accumulate temperature of $7000{ }^{\circ} \mathrm{C}$ $\left(\mathrm{T}=10^{\circ} \mathrm{C}\right.$ ) is $2500^{\circ} \mathrm{C}$. Annual sunshine duration and annual mean precipitation are $2,673 \mathrm{~h}$ and $500 \mathrm{~mm}$, respectively and most rainfall is received from July to September. The studied area with continental monsoon climate is suitable for crop plantation such as soybean, rice, corn and beet.

\section{EXPERIMENTAL}

Sampling methods and analysis: The locations of sampling points were determined by referring related data such as agricultural regionalization, product distribution and farmingpattern characteristics, combined with the topographic conditions in Sanjiang plain. Total of 277 samples were collected (Fig. 1) and the sampling depth was between 0-20 cm. Heavy metal concentration in soil sample was determined according to "Procedural Regulations Regarding the Environmental Quality Monitoring of Soil (NY/T 395-2000)". After air drying, grinding and sieving, the soil samples were digested by $\mathrm{HNO}_{3}{ }^{-}$ $\mathrm{HClO}_{4}-\mathrm{HF} . \mathrm{Pb}, \mathrm{Cd}$ and $\mathrm{Cr}$ concentrations in the digested samples were measured by atomic absorption spectrometry; As and $\mathrm{Hg}$ concentrations were determined by atomic fluorescence spectrometry ${ }^{13}$.

Data processing, geo-statistics and spatial analysis: Data processing and basic statistical analysis were performed using Excel 2010 and SPSS 18.0. Then, spatial distribution analysis of the five heavy metals was conducted using the GIS software Arc GIS 9.3 ${ }^{14}$.

Assessment of heavy metal pollution: Müller geoaccumulation index and Håkanson potential ecological risk index were used to evaluate heavy metal pollution, which can describe the influence of a single factor on heavy metal pollution, as well as the integrated influence of several factors on heavy metal pollution. As the most widely used methods in the world, these methods can quantify potential ecological risk ${ }^{15-18}$. For the evaluation, the background values of the five heavy metals were estimated as $\mathrm{Cd} 0.08, \mathrm{Hg} 0.03$, As 7.53, $\mathrm{Pb} 23.08, \mathrm{Cr}$ $51.57(\mathrm{mg} / \mathrm{kg})$, consistent with those tested by $\mathrm{Fu}$ and $\mathrm{Wu}^{19}$ in 1980. The book China Soil Background Value published the metal background value in all types of soil ${ }^{20}$ and soil type ratio could be attained from the book Jiamusi Soil ${ }^{21}$, so the background value of heavy metal in this study could be estimated according to the suggestion from some scientists.

The formula for Müller geoaccumulation index is expressed as follows ${ }^{22}$ :

$$
I_{\text {geo }}=\log _{2}\left[\frac{C_{n}}{\left(k \times B_{n}\right.}\right]
$$

where $C_{n}$ denotes the measured value of heavy metals; $B_{n}$ denotes the background value of each element in Sanjiang Plain; and k (normally set as 1.5 ) represents the coefficient describing the variation of background value due to rock difference. Igeo quantitatively classifies the state of heavy metal pollution into seven levels (Table-1).

\begin{tabular}{ccc}
\multicolumn{3}{c}{ TABLE-1 } \\
\multicolumn{3}{c}{ CLASSIFICATION OF THE MÜLLER } \\
GEOACCUMULATION INDEX \\
\hline Geoaccumulation index & Level & Pollution state \\
\hline$>5$ & 6 & Extremely serious \\
$4-5$ & 5 & Serious-extremely serious \\
$3-4$ & 4 & Serious \\
$2-3$ & 3 & Moderate-serious \\
$1-2$ & 2 & Moderate \\
$0-1$ & 1 & Light \\
$<0$ & 0 & None \\
\hline
\end{tabular}

The formula for Håkanson potential ecological risk index is given as follows ${ }^{23}$ :

$$
\mathrm{C}_{\mathrm{f}}^{\mathrm{i}}=\frac{\mathrm{C}_{\text {surface }}^{\mathrm{i}}}{\mathrm{C}_{\mathrm{n}}^{\mathrm{i}}}, \mathrm{C}_{\mathrm{d}}=\Sigma \mathrm{C}_{\mathrm{f}}^{\mathrm{i}}, \mathrm{E}_{\mathrm{r}}^{\mathrm{i}}=\mathrm{T}_{\mathrm{r}}^{\mathrm{i}} \times \mathrm{C}_{\mathrm{f}}^{\mathrm{i}}, \mathrm{RI}=\Sigma \mathrm{E}_{\mathrm{r}}^{\mathrm{i}}
$$

where $\mathrm{C}_{\mathrm{f}}^{\mathrm{i}}$ denotes individual pollution risk of single metal; $\mathrm{C}_{\text {surface }}^{\mathrm{i}}$ denotes the measured value of surface soil heavy metal content; $\mathrm{C}_{\mathrm{n}}{ }^{\mathrm{i}}$ is the background value of each element in Sanjiang Plain; $\mathrm{Cd}$ represents the comprehensive pollution risk of multiple metals; $\mathrm{E}_{\mathrm{r}}^{\mathrm{i}}$ denotes the individual potential ecological risk of single metal and $\mathrm{T}_{\mathrm{r}}^{\mathrm{i}}$ is the response coefficient of the heavy metal pollution toxicology of a single metal. According to the standards established by Håkanson and other researchers ${ }^{15,18}, \mathrm{~T}_{\mathrm{r}}^{\mathrm{i}}$ values of $\mathrm{Cd}, \mathrm{Hg}, \mathrm{As}, \mathrm{Pb}$ and $\mathrm{Cr}$ were set as $30,40,10,5$ and 2 , respectively. RI denotes the comprehensive potential ecological risk of multiple metals. This study only focused on five heavy metals, so the selected standards of 
pollution state assessment are slightly different from those in original Håkanson assessment (Table-2).

\section{RESULTS AND DISCUSSION}

Statistical analyses of heavy metal pollution: Statistical analyses were performed based on the detected heavy metal content of collected samples. The detection analysis confirmed that the requirement for quality control is satisfied. Table-3 shows the results of concentration statistical analysis of five heavy metals in the farmland soils of studied area 3 . The coefficients of variation $(\mathrm{CV})$ show that $\mathrm{Cd}$ and $\mathrm{As}$ have high variability, i.e., $\mathrm{Cd}$ and As exhibit 35 and $43 \% \mathrm{CV}$, respectively. The maximum $\mathrm{Pb}$ content reaches up to $34.8 \mathrm{mg} / \mathrm{kg}$ and $\mathrm{As}$ has a maximum value of $18.16 \mathrm{mg} / \mathrm{kg}$, which far exceeds the background value. The comparison of the average value of metallic element content with each background value shows that $\mathrm{Cd}$ and As visibly increase. The detected results are similar to those obtained for heavy metal content in Amur river basin, Russia $^{24}$.

Heavy metal correlation was carried out to determine whether the metal sources are identical. Table- 4 showed the $\mathrm{Cd}$ is correlated with $\mathrm{As}, \mathrm{Pb}$ and $\mathrm{Cr}$. The correlation coefficient between $\mathrm{Cd}$ and $\mathrm{As}$ is at 0.634 , indicating that they are highly correlated. The correlation coefficient of $\mathrm{As}$ and $\mathrm{Pb}$ is 0.593 . Additionally, As exhibits obvious correlation with $\mathrm{Hg}$ and $\mathrm{Cr}$. Judging from the level of correlation coefficients, Cd, As and $\mathrm{Pb}$ probably originate from the same source.

Cluster analysis involves the assignment of a set of observations into subsets called clusters, therefore, observations in the same cluster are similar to some degree and observations in different clusters have low similarities. Based on cluster analysis, the contents of five heavy metals in farmland soils of 21 villages in studied area can be classified into four categories (Fig. 2). The category (1) has the lowest heavy metal content in the soil, including the villages of BeiGang, ZhongRen, FuXing, FuQiang, LianSheng, BeiShan and XinFu. Category (2) also has low heavy metal content, including JieJinKou,

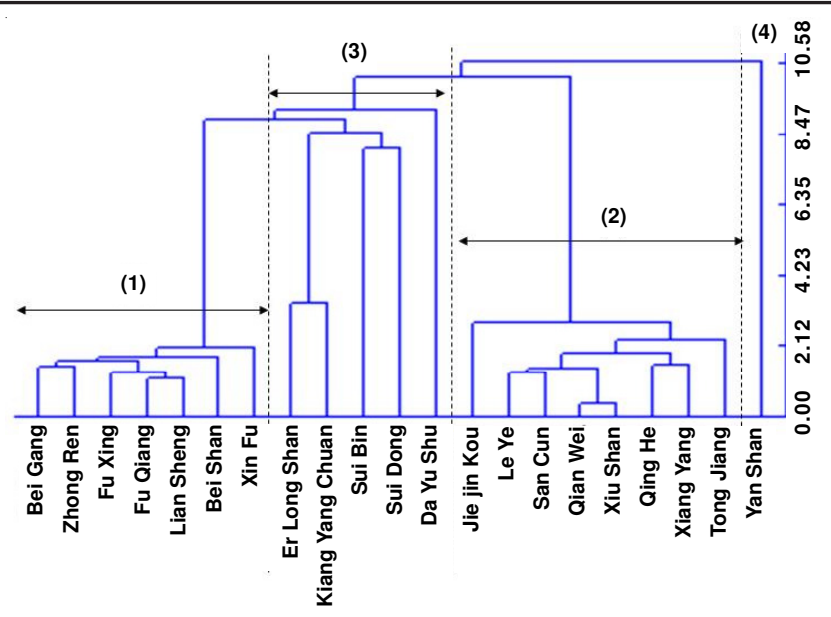

Fig. 2. Cluster analysis of the pollution level of heavy metal

Leye, Sancun, QianWei, XiuShan, QingHe, Tong Jinag and Xiang Yang. Categor (3) has relatively high heavy metal content, including ErLongShan, Xiang YangChuan, Sunbin, SunDong and Dayushu. Only YanShan County which has the highest heavy metal content composes the category (4).

Spatial distribution characteristics of five heavy metals: Inverse distance weighting (IDW) is an interpolation method in which values are assigned to unknown points using the values from a usually scattered set of known points. This method is based on the assumption that the interpolating surface is more influenced by nearby points and less by farer points. The interpolating surface is a weighted average of the scatter points and the weight assigned to each scatter point diminishes as the distance from the interpolation point to the scatter point increases. The spatial distributions of five heavy metals in the studied area (Fig. 3) were analyzed using the function geostatistical analyst of ArcGIS 9.3 by applying IDW. The levels of $\mathrm{Cd}$ and As are elevated in YanShan, Xiang YanChuan and ErLongShan. The levels of $\mathrm{Hg}$ are scattered and relatively high in Suibin Village. Lead is elevated in BeiShan in Suibin County, Xiang YanChuan and ErLongShan, the levels exceed the back-

\begin{tabular}{|c|c|c|c|c|c|c|c|}
\hline \multicolumn{8}{|c|}{$\begin{array}{c}\text { TABLE-2 } \\
\text { HÅKANSON INDICES }\left(\mathrm{C}_{\mathrm{f}}^{\mathrm{ii}}, \mathrm{C}_{\mathrm{d}}^{\mathrm{i}}, \mathrm{E}_{\mathrm{r}}^{\mathrm{ii}}, \mathrm{RI}\right) \text { AND CORRESPONDING RISK LEVELS }\end{array}$} \\
\hline \multicolumn{2}{|c|}{ Individual pollution risk } & \multicolumn{2}{|c|}{ Comprehensive pollution risk } & \multicolumn{2}{|c|}{$\begin{array}{l}\text { Comprehensive potential } \\
\text { ecological risk }\end{array}$} & \multicolumn{2}{|c|}{$\begin{array}{l}\text { Comprehensive potential } \\
\text { ecological risk }\end{array}$} \\
\hline $\mathrm{C}_{\mathrm{f}}^{\mathrm{i}}<1$ & Low & $\mathrm{C}_{\mathrm{d}}<5$ & Low & $\mathrm{E}_{\mathrm{r}}^{\mathrm{i}}<40$ & Low & $\mathrm{RI}<150$ & Low \\
\hline $1 \leq \mathrm{C}_{\mathrm{f}}^{\mathrm{i}}<3$ & Moderate & $5 \leq \mathrm{C}_{\mathrm{d}}<10$ & Moderate & $40 \leq \mathrm{E}_{\mathrm{r}}^{\mathrm{i}}<80$ & Moderate & $150 \leq \mathrm{RI}<300$ & Moderate \\
\hline $3 \leq \mathrm{C}_{\mathrm{f}}^{\mathrm{i}}<6$ & Relatively high & $10 \leq C_{d}<20$ & Relatively high & $80 \leq \mathrm{E}_{\mathrm{r}}^{\mathrm{i}}<160$ & Relatively high & $300 \leq \mathrm{RI}<600$ & Relatively high \\
\hline $\mathrm{C}_{\mathrm{f}}^{\mathrm{i}} \geq 6$ & Extremely high & $\mathrm{C}_{\mathrm{d}} \geq 20$ & Extremely high & $1600 \leq \mathrm{E}_{\mathrm{r}}^{\mathrm{i}}<320$ & High & $\mathrm{RI} \geq 600$ & Extremely high \\
\hline- & - & - & - & $\mathrm{E}_{\mathrm{r}} \geq 320^{\mathrm{i}}$ & Extremely high & - & - \\
\hline
\end{tabular}

TABLE-3

STATISTICAL ANALYSIS OF DETECTED FIVE HEAVY METAL CONTENT IN FARMLAND SOILS OF STUDIED AREA

\begin{tabular}{|c|c|c|c|c|c|c|c|c|c|}
\hline & $\begin{array}{l}\text { Samples } \\
\text { number }\end{array}$ & $\begin{array}{l}\text { Range } \\
(\mathrm{mg} / \mathrm{kg})\end{array}$ & $\begin{array}{l}\text { Average } \\
\left(\mathrm{mg} / \mathrm{kg}^{-1}\right)\end{array}$ & $\begin{array}{l}\text { Standard } \\
\text { deviation }\end{array}$ & $\begin{array}{l}\text { Coefficient of } \\
\text { variation }(\%)\end{array}$ & $\begin{array}{l}\text { Asymmetry } \\
\text { coefficient }\end{array}$ & $\begin{array}{c}\text { Kurtosis } \\
\text { coefficient }\end{array}$ & $\begin{array}{c}\text { Background } \\
\text { value* }\left(\mathrm{mg} / \mathrm{kg}^{-1}\right)\end{array}$ & $\begin{array}{l}\text { Standardized limit } \\
\text { value** }^{*}(\mathrm{mg} / \mathrm{kg})\end{array}$ \\
\hline $\mathrm{Cd}$ & 277 & $0.048-0.28$ & 0.17 & 0.06 & 35 & -0.06 & 1.89 & 0.08 & 0.3 \\
\hline $\mathrm{Hg}$ & 277 & $0.017-0.07$ & 0.039 & 0.008 & 21 & 0.77 & 6.4 & 0.03 & 0.5 \\
\hline As & 277 & 9 & 11.2 & 4.8 & 43 & 0.15 & 1.5 & 7.53 & Paddy 25 , field 30 \\
\hline $\mathrm{Pb}$ & 277 & $4.73-18.16$ & 21.98 & 3.88 & 17.6 & 0.29 & 2.02 & 23.08 & 300 \\
\hline $\mathrm{Cr}$ & 277 & $15.9-34.8$ & 36.2 & 12.01 & 33.2 & 0.06 & 1.6 & 51.57 & Paddy 300 , field \\
\hline- & - & $16.8-55.1$ & - & - & - & - & - & - & 200 \\
\hline
\end{tabular}

*Local background value is obtained from China Soil Background Value (State Environmental Protection Administration, 1990); **People's Republic of China "environmental condition standards for pollution-free food production (NY5332-2006)" standards, where PH 6.5-7.5 was selected. 
TABLE-4

CORRELATION COEFFICIENT OF FIVE METAL ELEMENTS

\begin{tabular}{ccccc} 
Element & $\mathrm{Cd}$ & $\mathrm{Hg}$ & $\mathrm{As}$ & $\mathrm{Pb}$ \\
$\mathrm{Cd}$ & 1 & - & - & - \\
$\mathrm{Hg}$ & 0.086 & 1 & - & - \\
$\mathrm{As}$ & $0.634^{* *}$ & $0.324^{* *}$ & 1 & - \\
$\mathrm{Pb}$ & $0.384^{* *}$ & $0.318^{* *}$ & $0.593^{* *}$ & 1 \\
$\mathrm{Cr}$ & $0.384^{* *}$ & -0.044 & $-0.41^{* *}$ & $-0.134^{*}$ \\
\hline
\end{tabular}

**Significance level: 0.01
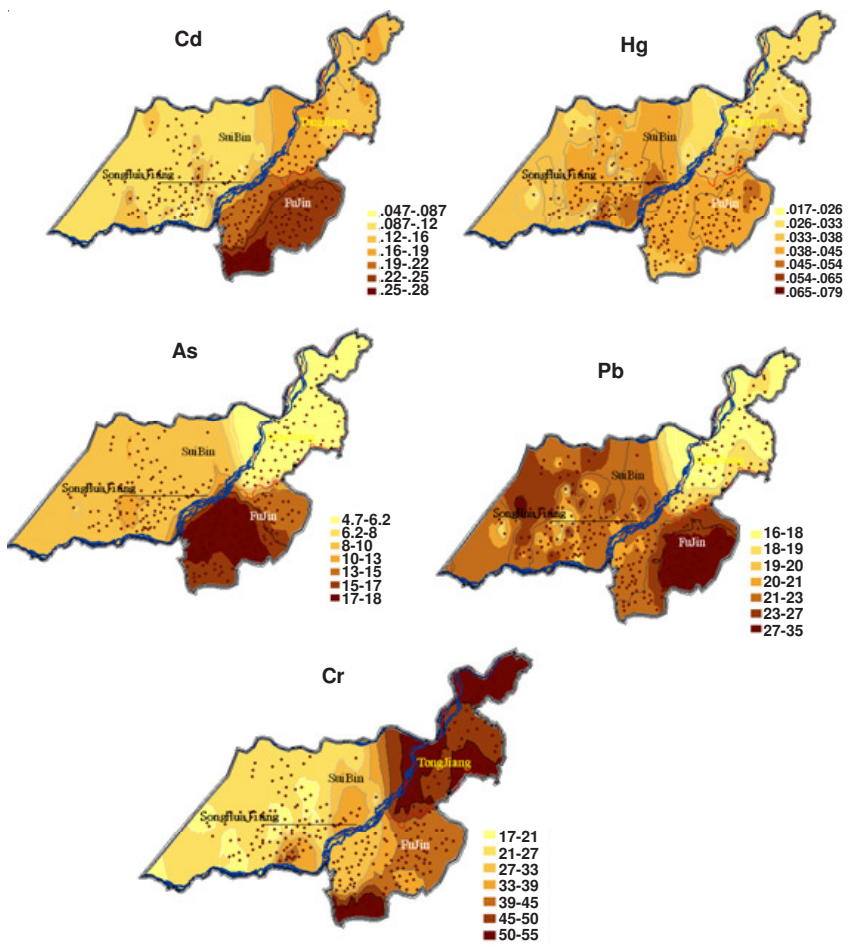

Fig. 3. Spatial distribution characteristics of the five heavy metals

ground value. The Cr levels are elevated in JieJinKou, XiuShan, Tongjiang, QianWei and YanShan. The distributions of $\mathrm{Cd}$, $\mathrm{As}$ and $\mathrm{Pb}$ have similarities that concentrate around YanShan County in Fujing City. Mercury distribution is scattered and $\mathrm{Cr}$ levels are relatively high especially in villages of TongJiang City.

Potential ecological risk assessment of the five heavy metals: The geoaccumulation index method was first proposed by Müller $^{21}$. It is a quantitative index to assess the state of heavy metal pollution, especially in sediment. It is universally adopted in Europe and many researchers in China have also adopted this method. Based on Müller index, we confirmed that for $\mathrm{Cd}, 77$ of 277 samples are unpolluted, 185 are lightly polluted and 16 exhibit moderate pollution. For $\mathrm{Hg}, 266$ of 277 are unpolluted and 11 are lightly polluted. For As, 163 samples are unpolluted and 114 are lightly polluted. $\mathrm{Pb}$ and $\mathrm{Cr}$ have no pollution.

The potential ecological risk assessment index method was established by Swedish researcher Håkanson, which assessed heavy metal pollution and ecological risk in accordance with sediment logical theory (Håkanson, 1980) ${ }^{23}$. The RI (risk index) is affected by following factors: (1) surface density of sediment, (2) type of heavy metals, (3) toxicology of heavy metals and (4) sensitivity of intended water to heavy metals. According to Cfi value of the Håkanson method $^{23}$, the level of ecological risk caused by each single factor is assessed as follows: Cd contents in the sampling spots are assessed as no risk to 20 spots, moderate-level risk to 227 spots and relatively high-level risk to 30 spots. Mercury poses no risk to 57 spots and normal-level risk to 220 spots. As poses no risk to 77 spots and normal-level risk to 200 spots, whereas $\mathrm{Pb}$ presents no risk to 175 spots and normal-level risk to 102 spots. Finally, Cr poses no risk to 233 spots and normal-level risk to 44 spots. Additionally, judging from $\mathrm{Cd}$ value, the comprehensive pollution level caused by the five heavy metals indicates that 33 out of all sampling spots are unpolluted and 244 have normal pollution levels. Moreover, the calculated risk index value, which was used to assess the potential ecological risk caused by the five metals, indicates that 168 of the sampling spots are unpolluted and 109 exhibit normal pollution. The risk index value distribution of the entire studied area, calculated using the interpolated value of heavy metal content, is shown in Fig. 4. The spots exposed to normal risk are concentrated in Fujing city.

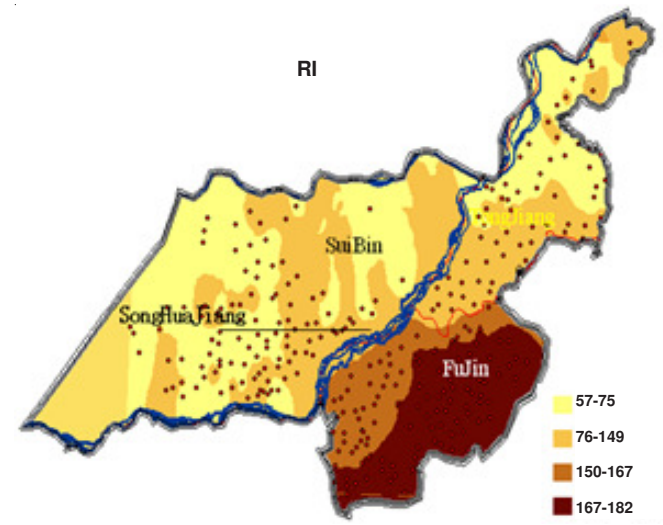

Fig. 4. Distribution of calculated RI values in the studied area

According to the assessment by the Müller and Håkanson risk indices, the influence of the heavy metals in terms of ecological risk follows the order $\mathrm{Cd}>\mathrm{Hg}>\mathrm{As}>\mathrm{Pb}>\mathrm{Cr}$. The risk index values of Fujing City, Tongjiang City and Suibin County are 168.1, 111.1 and 109.6, respectively; Fujing City is exposed to moderate risk while other cities are exposed to low risk. Given that these three districts primary rely on agriculture industry, prolonged cultivation, excessive fertilizer and pesticide usages and adjacent to roads, have resulted in high heavy metal accumulation. Conversely, less fertilizer and pesticide usages and shorter cultivation period may result in lower accumulation of heavy metals in southern area of confluence zone.

\section{Conclusion}

The measurement results of $\mathrm{Cd}, \mathrm{Hg}, \mathrm{As}, \mathrm{Pb}$ and $\mathrm{Cr}$ content in farmland soils at the confluence zone of Heilong and Songhua Rivers confirmed that the concentrations of these heavy metals in the area are within the agricultural industry standards of China or the Environmental Condition Standards for Pollution-Free Food Production (NY5332-2006). The present paper concluded that studied area can be classified as a clean agricultural area. Furthermore, necessary conditions for pollution-free farming are satisfied in the area, enabling 
high-quality agricultural production. However, $\mathrm{Cd}$ and $\mathrm{As}$ contents have relatively higher values compared with local background values. The distribution analysis of five heavy metals indicated that heavy metal contents are primarily concentrated around Fujing City. The heavy metal accumulation is inferred to be caused by leaching from soil and transferring from low-lying areas during the rainy season. The enrichment of $\mathrm{Cd}$ and As results from agricultural overdevelopment and excessive fertilizer and pesticide usages. In addition, the ecological risk assessment confirmed that the influence of the heavy metals in terms of ecological risk follows the order $\mathrm{Cd}$ $>\mathrm{Hg}>\mathrm{As}>\mathrm{Pb}>\mathrm{Cr}$. Cadmium and mercury contents should be particularly studied further.

\section{ACKNOWLEDGEMENTS}

This work was supported by the Promotion Plan 2005 for Heilongjiang Non-Pollution Agricultural Products and the Science \& Technology Fund of Jiamusi University (L2012067). The authors thank the scientists as follows for their kindly help (in alphabetic order): Gu Yi-ming (Chief Engineer, Geography Information Center of Heilongjiang), Li Lin-shan (Chief Engineer, The Sixth Institute of Heilongjiang Geological Survey), Liu Cheng (Professor, International Research and Training Center on Erosion and Sedimentation) Mao Ren-zhao (Researcher, Center for Agricultural Resources Research), Yu Zhong-he (Researcher, Jiamusi Agricultural Institute), Zhao Chun-guang (Head, Jiamusi Institute of Geological Survey).

\section{REFERENCES}

1. A. Kaya and H. Bag, Asian J. Chem., 22, 1515 (2010).

2. M.A. Ebrahimzadeh, S.M. Nabavi, S.F. Nabavi, S. Eslami and A.R. Bekhradnia, Asian J. Chem., 22, 6257 (2010).
3. N. Gebologlu, S.C. Cetin, A. Ece, E. Yilmaz and M. Elmastas, Asian J. Chem., 17, 730 (2005).

4. C.G. Affonso, N. Herbert, S. Daniel, A.N. Ivair and S. Leonardo, Water Air Soil Pollut., 220, 205 (2011).

5. H.Y. Liu, S.K. Zhang, Z.F. Li, X.G. Lu and Q. Yang, Ambio, 33, 306 (2004).

6. J.Y. Zhang, K.M. Ma and B.J. Fu, Environ. Monit. Assess., 166, 139 (2010).

7. Z.M. Wang, B. Zhang, S.Q. Zhang, X.Y. Li, D.W. Liu, K.S. Song, J.P. Li, F. Li and H.T. Duan, Environ. Monit. Assess., 112, 69 (2006).

8. Y.N. Liu, G.T. Yang, Z.Y. Yan, J.F. Wang and H.W. Ni, In Proceedings of International Symposium on Water Resource and Environmental Protection (ISWREP), Xi'an, China, pp. 3078-3081 (2011).

9. T. Lu, K.M. Ma, H.W. Ni, B.J. Fu, J.Y. Zhang and Q. Lu, Acta Ecol. Sin., 28, 1893 (2008).

10. J.H. Wang, X.G. Lu, M. Jiang, X.Y. Li and J.H. Tian, Pedosphere, 19, 756 (2009).

11. J.B. Zhang, C.C. Song and W.Y. Yang, Chemosphere, 59, 1703 (2005).

12. C.C. Song, Y.S. Wang, Y.Y. Wang and Z.C. Zhao, Atmos. Environ., 40, 6879 (2006).

13. S.S. Huang, Q.L. Liao, M. Hua, X.M. Wu, K.S. Bi, C.Y. Yan, B. Chen and X.Y Zhang, Chemosphere, 67, 2148 (2007).

14. B.F. Di, N.S. Chen, P. Cui, Z.L. Li, Y.P. He and Y.C. Gao, Int. J. Sediment Res., 23, 138 (2008).

15. C. Herr and N.F. Gray, Environ. Geol., 29, 37 (1997).

16. C. Liu, Z.Y. Wang and C.H. Hu, Int. J. Sediment Res., 18, 223 (2003).

17. J. Peng, Z.Q. Li and J.Y. Hou, Guangdong Trace Elements Sci., 14, 13 (2007).

18. L.G. Zheng, G. J. Liu, Y. Kang and R.K Yang, Environ. Monit. Assess., 166, 379 (2010).

19. D.Y. Fu and D.H. Wu, Chin. J. Soil Sci., 1, 26 (1982).

20. State Environmental Protection Administration, China Soil Background Value, China Environmental Science Press, Beijing, pp. 97-132 (1990).

21. J.C. Xi, Jiamusi Soil, Heilongiiang Science \& Technology Press, China, pp. 21-179 (1988).

22. G. Müller, Schwermetalle in den Sedimenten des Rheins-Veränderungen Seit 1971, Umschau, 79, pp. 107-126 (1979).

23. L. Håkanson, Water Res., 14, 975 (1980).

24. O. Prosyannikova and V.I. Prosyannikov, Bull. Altai State Agric. Univ., 72, 22 (2010). 